\title{
Neurodevelopmental Outcomes After Cardiac Surgery in Infancy
}

J. William Gaynor, MDa, Christian Stopp, MS , David Wypij, PhD ${ }^{b}$, Dean B. Andropoulos, MDc, Joseph Atallah, MD, CM, SM, FRCPC Andrew M. Atz, MDe, John Beca, MD', Mary T. Donofrio, MD, Kim Duncan, MD ${ }^{\mathrm{h}}$, Nancy S. Ghanayem, MDi, Caren S. Goldberg, MD',

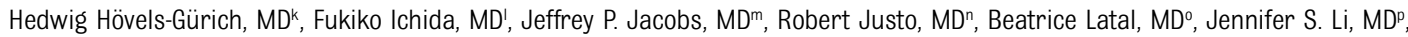
William T. Mahle, MD', Patrick S. McQuillen, MDr, Shaji C. Menon, MD's, Victoria L. Pemberton, RNC, MS, CCRC' , Nancy A. Pike, RN, PhD ${ }^{4}$,

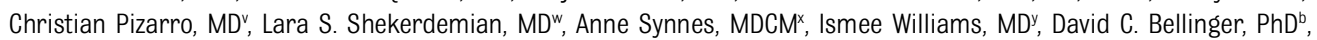
Jane W. Newburger, MD, MPH', for the International Cardiac Collaborative on Neurodevelopment (ICCON) Investigators

BACKGROUND: Neurodevelopmental disability is the most common complication for survivors of surgery for congenital heart disease (CHD).

METHODS: We analyzed individual participant data from studies of children evaluated with the Bayley Scales of Infant Development, second edition, after cardiac surgery between 1996 and 2009. The primary outcome was Psychomotor Development Index (PDI), and the secondary outcome was Mental Development Index (MDI).

RESULTS: Among 1770 subjects from 22 institutions, assessed at age $14.5 \pm 3.7$ months, PDIs and MDIs (77.6 \pm 18.8 and 88.2 \pm 16.7 , respectively) were lower than normative means (each $P<.001$ ). Later calendar year of birth was associated with an increased proportion of high-risk infants (complexity of CHD and prevalence of genetic/extracardiac anomalies). After adjustment for center and type of CHD, later year of birth was not significantly associated with better PDI or MDI. Risk factors for lower PDI were lower birth weight, white race, and presence of a genetic/extracardiac anomaly (all $P \leq .01)$. After adjustment for these factors, PDIs improved over time (0.39 points/year, $95 \%$ confidence interval 0.01 to $0.78 ; P=.045$ ). Risk factors for lower MDI were lower birth weight, male gender, less maternal education, and presence of a genetic/extracardiac anomaly (all $P<.001$ ). After adjustment for these factors, MDIs improved over time $(0.38$ points/year, $95 \%$ confidence interval 0.05 to $0.71 ; P=.02$ ).

CONCLUSIONS: Early neurodevelopmental outcomes for survivors of cardiac surgery in infancy have improved modestly over time, but only after adjustment for innate patient risk factors. As more high-risk CHD infants undergo cardiac surgery and survive, a growing population will require significant societal resources.

\section{WHAT'S KNOWN ON THIS SUBJECT:}

Neurodevelopmental disabilities are the most common, and potentially the most damaging, sequelae of congenital heart defects. Children with congenital heart defects undergoing surgery in infancy have problems with reasoning, learning, executive function, inattention and impulsive behavior, language skills, and social skills.

\section{WHAT THIS STUDY ADDS: Early}

neurodevelopmental outcomes for survivors of cardiac surgery in infancy have improved modestly over time, but only after adjustment for innate patient risk factors. As more high-risk infants with congenital heart defects survive cardiac surgery, a growing population will require significant societal resources.
${ }^{a}$ The Children's Hospital of Philadelphia, Philadelphia, Pennsylvania; ${ }^{b}$ Boston Children's Hospital, Boston, Massachusetts; ${ }^{c}$ Texas Children's Hospital, Houston, Texas; ${ }^{d}$ Stollery Children's Hospital and the Western Canadian Complex Pediatric Therapies Follow-up Program, Edmonton, Alberta, Canada; ${ }^{e}$ Division of Pediatric Cardiology, Medical University of South Carolina, Charleston, South Carolina; ${ }^{f}$ Starship Children's Hospital, Auckland, New Zealand; ${ }^{g}$ Children's National Medical Center, Washington, District of Columbia; ${ }^{h}$ Children's Hospital and Medical Center, Omaha, Nebraska; 'Medical College of Wisconsin, Children's Hospital of Wisconsin, Milwaukee, Wisconsin; 'Mott's Children's Hospital, Ann Arbor, Michigan; ' University Hospital Aachen, Aachen, Germany; 'Toyama University Hospital, Toyama, Japan; ' ${ }^{m} J o h n s$ Hopkins All Children's Heart Institute, St. Petersburg, Florida; ${ }^{n}$ University of Queensland, Brisbane, Australia; ${ }^{\circ}$ University Children's Hospital Zurich, Zurich, Switzerland; ${ }^{p}$ Duke University Medical Center, Durham, North Carolina; ${ }^{a}$ Children's Healthcare of Atlanta, Atlanta, Georgia; ' University of California, San Francisco, San Francisco, California; 's Primary Children's Medical Center, Salt Lake City, Utah; ${ }^{t}$ National Heart, Lung, and Blood Institute, Bethesda, Maryland; "Children's Hospital Los Angeles, Los Angeles, California; ' Alfred I. duPont Hospital for Children, Wilmington, Delaware; 'The Royal Children's Hospital, Melbourne, Australia; ${ }^{x}$ University of British Columbia, Vancouver, British Columbia, Canada; and ${ }^{y}$ New YorkPresbyterian Morgan Stanley Children's Hospital of New York, New York, New York

Drs Gaynor and Newburger conceptualized and participated in design of the study; Drs Gaynor, Newburger, Bellinger, and Hövels-Gürich and Ms Pemberton contributed to data interpretation; Drs Andropoulos, Atallah, Atz, Beca, Donofrio, Duncan, Ghanayem, Goldberg, Ichida, Jacobs, Justo, Latal, Li, Mahle, McQuillen, Menon, Pike, Pizarro, Shekerdemian, Synnes, and Williams supervised data collection and submission at their institutions (including participation in the Pediatric Heart Network Single Ventricle Reconstruction [SVR] and Infant Single Ventricle [ISV] trials,); 
Neurodevelopmental disabilities are the most common, and potentially the most damaging, sequelae of complicated childhood diseases. Although many studies have evaluated the cognitive and behavioral status of children who were born prematurely, few have been performed in children suffering from rare conditions including complex congenital heart disease (CHD). ${ }^{1}$ Small studies at individual institutions have shown that children with CHD undergoing surgery in infancy have more problems with reasoning, learning, executive function, inattention and impulsive behavior, language skills, and social skills compared with peers without CHD. ${ }^{2-5}$ Lower abilities in these areas may lead to poor school performance, strained interpersonal relationships, and behavior problems. Survivors of cardiac surgery in infancy are more likely than the general population to require remedial services, including tutoring and special education, as well as physical, occupational, and speech therapy. ${ }^{2,6}$ As these children reach adulthood, neurodevelopmental disabilities can limit educational achievements, employability, insurability, and quality of life. Currently known risk factors explain only $\sim 30 \%$ of the observed variation in neurodevelopmental outcome after cardiac surgery in infancy. ${ }^{7}$ Importantly, these studies have identified few modifiable risk factors for adverse neurodevelopmental outcomes. $^{7-9}$ In addition, these studies usually derive from single centers and are limited by small sample size.

Many centers caring for children with CHD have measured and reported neurodevelopmental outcomes, often using standardized instruments and collecting similar data on potential covariates and confounders. The use of individual participant data from multiple studies has been championed as the gold standard for synthesizing prognostic risk factors in clinical prediction models. ${ }^{10-12}$
Nevertheless, no studies using this approach have been performed in children with CHD or have evaluated neurodevelopmental outcomes. In this study, we pooled and analyzed such data from earlier studies to describe neurodevelopmental outcomes of infants after open cardiac surgery with regard to temporal trends over a 14-year interval.

\section{METHODS}

\section{Identification of Participating Institutions}

Participating institutions were selected based on a literature search to identify studies reporting neurodevelopmental outcomes after cardiac surgery in infancy (Supplemental Table 4). The inclusion criteria were (1) cardiac surgery using cardiopulmonary bypass at age $\leq 9$ months; (2) enrollment in a clinical trial or observational cohort study with date of surgery between January 1, 1988, and December 31, 2009; (3) neurodevelopmental evaluation between 6 and 30 months of age using the Bayley Scales of Infant Development, first edition (BSID-I), BSID-II, or the Bayley Scales of Infant and Toddler Development, third edition ${ }^{13,14}$; and (4) data available on patient and operative management variables. Children treated with a primary strategy of cardiac transplantation were not eligible. Investigators identified by the initial literature search were contacted and invited to participate. Additional centers with eligible subjects but previously unpublished data were identified and invited to contribute. All invited investigators agreed to submit data for this analysis. ${ }^{8,9,15-24}$

\section{Preparation of the Analysis Data Set}

Participating institutions reviewed their databases to select appropriate subjects for analysis. Each institution obtained approval or exemption from their institutional review board.
Center investigators submitted a limited, deidentified standardized dataset, including neurodevelopmental outcome measures and demographic, preoperative, perioperative, and postoperative variables

(Supplemental Table 5). Investigators were asked to code their subjects according to cardiac diagnosis into 1 of 4 previously described categories that have been shown to predict perioperative mortality: Class I, 2 ventricles with no aortic arch obstruction; Class II, 2 ventricles with aortic arch obstruction; Class III, single ventricle without arch obstruction; and Class IV, single ventricle with arch obstruction. ${ }^{25}$ Subjects with d-transposition of the great arteries (TGA) or tetralogy of Fallot (TOF) are generally in Class I, whereas subjects with hypoplastic left heart syndrome (HLHS) are in Class IV. Subgroup analyses were performed based on 3 common types of CHD: TGA with intact ventricular septum (IVS) or ventricular septal defect (VSD) (Class I only), TOF with or without pulmonary atresia (PA), and HLHS. Anomalies were classified as definite genetic anomalies, suspected genetic anomalies or major extracardiac anomalies, or absent (normal). Subjects in whom the presence or absence of an anomaly had not been specifically noted were classified as being normal.

The sample was restricted to subjects assessed using BSID-II, which was the most commonly used instrument. Although the sample would have been larger had other versions of the Bayley scales been included, no standardized methodology exists by which scores from different versions of the Bayley scales can be combined. BSID-II offers a standardized assessment of cognitive and motor development for children aged 1 through 42 months. It yields 2 scores: the Psychomotor Development Index (PDI) and the Mental Development Index (MDI). The PDI assesses control of gross muscle function, including 
crawling and walking, as well as fine muscle skills necessary for prehension, use of writing instruments, and imitation of hand movements. The MDI assesses memory, problem solving, early number concepts, generalization, vocalizations, and language and social skills. The mean \pm SD is $100 \pm 15$ in the normative population for both scores. Motor skills (PDI) are usually more severely affected in infant survivors of cardiac surgery than are cognitive abilities (MDI). ${ }^{15,21}$

\section{Dataset Preparation and Statistical Analysis}

Center investigators reviewed their data for deidentification, data accuracy, data completeness, and outlying observations before submission to the Data Coordination Center (DCC) at Boston Children's Hospital. The DCC performed a standardized integrity examination of the data to identify inconsistencies, missing data, and outliers across institutions. Communications were exchanged with centers until all issues were resolved. Collaborative decisions between the lead investigators (Drs Gaynor and Newburger) were made with respect to group assignment for cardiac class, cardiac diagnosis, race, and genetic anomaly when collapsing across categories of a variable or handling unique cases. Analyses included only data for which all queries had been resolved. The DCC merged the data across institutions into a final analysis data set.

Group differences by cardiac class were assessed by using $\chi^{2}$ tests for categorical variables and analysis of variance or Kruskal-Wallis tests for continuous variables. Comparisons of PDI and MDI with normative means were made using 1-sample $t$ tests. Primary analyses examined the relationships of PDI and MDI from BSID-II with year of birth. Pearson correlations were used to examine these relationships in the full cohort as well as in homogeneous diagnostic subgroups (ie, TGA, TOF, and HLHS). The types of CHD included in clinical studies changed over time. Therefore, linear regression analyses using continuous year of birth and adjusting for center and cardiac class served as foundation models for predicting PDI and MDI. Candidate predictors in multivariable analyses were preoperative measures and patient factors, including birth weight, gestational age, race, ethnicity (Hispanic versus not Hispanic), gender, maternal education, genetic or extracardiac anomalies, prenatal diagnosis, preoperative mechanical ventilation, and neonatal status (age at first surgery $\leq 30$ days). Factors relating to operative management or postoperative course were not included. Predictors were screened to identify associations with a neurodevelopmental score at the $P<.25$ level after adjusting for center, cardiac class, and year of birth. Predictors meeting this criterion were included in stepwise backward analysis in which $P<.05$ served as the criterion for retention into the full model. Center, cardiac class, and year of birth were retained in all models regardless of $P$ value. Standardized mean scores present the predicted PDIs and MDIs adjusting for center, cardiac class, and other statistically significant predictors at the mean value of the covariates. Analyses were performed using SAS 9.3 (SAS Institute, Cary, NC).

\section{RESULTS}

Of the 2501 subjects submitted from 26 institutions in 6 countries, 1770 subjects born between 1996 and 2009 from 22 institutions were evaluated with BSID-II and form the cohort for this report. The cohort was predominantly male $(61.5 \%)$, white (84.0\%), and non-Hispanic (92.3\%). Cardiac diagnoses and preoperative characteristics are shown in Table 1 for the overall cohort and each class of CHD. Because of changes in eligibility criteria across studies, the majority of subjects in the early years were in Class I, whereas in later years, the percentage of subjects in Class IV surpassed that in Class I (Fig 1A). The most common cardiac defects were HLHS ( $n=549,31.0 \%$ ), followed by TGA with IVS ( $n=235,13.3 \%$ ), other single ventricle $(n=203,11.5 \%)$, TOF without PA ( $n=166,9.4 \%)$, VSD $(n=$ $148,8.4 \%)$, and TGA with VSD ( $n=$ $121,6.8 \%$ ). Figure 1B shows variation over time in the percentage of subjects with a definite or suspected genetic or major extracardiac anomaly.

Subjects were assessed at age $14.5 \pm$ 3.7 months. Compared with normative means, CHD subjects had significantly lower PDIs (77.6 \pm 18.8) and MDIs (88.2 \pm 16.7 ) (each $P<$ $.001)$. PDIs and MDIs were $\geq 1$ SD below the population mean for $63.5 \%$ and $36.1 \%$ of subjects, respectively, and $\geq 2$ SD below the mean for $36.8 \%$ and $15.3 \%$ of subjects. Higher cardiac class, reflecting more serious heart disease, was significantly associated with lower PDI, but not with lower MDI (Table 1).

\section{Univariate analyses}

For the entire cohort, later year of birth was not associated with better PDI or MDI. Over the study period, unadjusted mean PDIs declined ( $r=$ $-0.17, P<.001)$, as did unadjusted MDIs ( $r=-0.05, P=.03)$. Similarly, in diagnostic subgroup analysis (TGA with IVS or VSD [Class I only], TOF with or without PA, and HLHS), unadjusted scores did not improve over time in any subgroup. PDIs declined over time for subjects with TGA $(r=-0.18, P=.001)$ and TOF $(r=-0.16, P=.03)$ but were stable for subjects with HLHS $(r=0.03, P=.44)$. MDIs decreased for the TOF group $(r=-0.16, P=.03$ ) but did not change significantly over time among those with TGA or HLHS (TGA: $r=-0.02$, $P=.68$; HLHS: $r=0.005, P=.91$ ).

\section{Multivariable analyses}

Multivariable analyses adjusting for center, cardiac class, and year of birth 
TABLE 1 Demographic and Preoperative Characteristics and Neurodevelopmental Outcomes by Cardiac Class

\begin{tabular}{|c|c|c|c|c|c|c|}
\hline Variable & Overall $(n=1770)$ & Class I $(n=878)$ & Class II $(n=114)$ & Class III $(n=106)$ & Class IV $(n=672)$ & $P$ \\
\hline \multicolumn{7}{|l|}{ Demographic and preoperative characteristics } \\
\hline Cardiac diagnosis & & & & & & - \\
\hline TGA/IVS & 13.3 & 26.5 & 1.8 & 0 & 0 & - \\
\hline TGA/VSD & 6.8 & 13.3 & 3.5 & 0 & 0 & - \\
\hline TOF & 9.4 & 18.7 & 0 & 1.9 & 0 & - \\
\hline TOF/PA & 1.3 & 1.8 & 0 & 6.6 & 0 & - \\
\hline TAPVC & 3.2 & 6.3 & 0 & 0.9 & 0 & - \\
\hline VSD without IAA/coarctation & 8.4 & 16.9 & 0 & 0 & 0 & - \\
\hline VSD with IAA/coarctation & 3.1 & 0 & 47.4 & 0 & 0.2 & - \\
\hline AVC defects & 3.1 & 5.4 & 5.3 & 0.9 & 0 & - \\
\hline HLHS & 31.0 & 0 & 0 & 0 & 81.7 & - \\
\hline Other functional single ventricle anomaly & 11.5 & 0 & 0 & 76.4 & 18.2 & - \\
\hline Other & 9.0 & 11.2 & 42.1 & 13.2 & 0 & - \\
\hline Birth weight (kg) & $3.2(0.6)$ & $3.2(0.7)$ & $3.2(0.6)$ & $3.1(0.6)$ & $3.3(0.5)$ & .10 \\
\hline Gestational age (wk) & $38.7(1.9)$ & $38.8(2.1)$ & $38.9(1.8)$ & $38.4(1.7)$ & $38.5(1.5)$ & $<.001$ \\
\hline Race & & & & & & $<.001$ \\
\hline White & 84.0 & 83.7 & 82.5 & 76.4 & 85.9 & - \\
\hline Black & 7.6 & 5.6 & 9.6 & 13.2 & 9.1 & - \\
\hline Other & 8.4 & 10.7 & 7.9 & 10.4 & 5.1 & - \\
\hline Hispanic ethnicity & 7.7 & 4.9 & 2.6 & 10.5 & 11.9 & $<.001$ \\
\hline Female gender & 38.5 & 40.1 & 44.7 & 36.8 & 35.6 & .15 \\
\hline Maternal education & & & & & & $<.001$ \\
\hline Graduate school & 11.3 & 11.9 & 11.4 & 9.4 & 10.9 & - \\
\hline Completed college & 24.4 & 26.3 & 28.9 & 5.7 & 24.1 & - \\
\hline High school and/or some college & 38.8 & 38.7 & 33.3 & 34.0 & 40.5 & - \\
\hline Less than high school & 8.3 & 8.5 & 9.6 & 3.8 & 8.5 & - \\
\hline Missing or not specified & 17.2 & 14.6 & 16.7 & 47.2 & 16.1 & - \\
\hline Genetic anomaly & & & & & & $<.001$ \\
\hline Normal or not specified & 85.1 & 86.9 & 69.3 & 93.4 & 84.2 & - \\
\hline Suspected genetic or major extracardiac & 6.6 & 2.9 & 6.1 & 1.9 & 12.2 & - \\
\hline Definite genetic & 8.3 & 10.3 & 24.6 & 4.7 & 3.6 & - \\
\hline Prenatal diagnosis & 38.5 & 16.1 & 28.4 & 49.2 & 70.0 & $<.001$ \\
\hline Preoperative mechanical ventilation & 35.2 & 28.6 & 39.5 & 41.4 & 55.1 & $<.001$ \\
\hline Neonate (age $\leq 30 \mathrm{~d}$ ) at time of surgery & 71.9 & 53.1 & 80.7 & 53.8 & 97.8 & $<.001$ \\
\hline \multicolumn{7}{|l|}{ Neurodevelopmental outcomes } \\
\hline Age at assessment (mo) & $14.5(3.7)$ & $14.4(3.9)$ & $15.6(5.2)$ & $14.3(4.0)$ & $14.6(3.1)$ & $<.001$ \\
\hline \multicolumn{7}{|l|}{ BSID-II } \\
\hline PDI & $77.6(18.8)$ & $80.6(18.3)$ & $79.2(20.3)$ & $76.3(17.8)$ & $73.7(18.7)$ & $<.001$ \\
\hline$\leq 85$ & 63.5 & 57.7 & 62.9 & 73.8 & 69.4 & $<.001$ \\
\hline$\leq 70$ & 36.8 & 30.0 & 31.4 & 36.9 & 46.4 & $<.001$ \\
\hline MDI & $88.2(16.7)$ & $88.3(16.1)$ & 86.0 (17.3) & $90.5(14.8)$ & 88.0 (17.6) & .24 \\
\hline$\leq 85$ & 36.1 & 34.8 & 40.4 & 26.4 & 38.7 & .05 \\
\hline$\leq 70$ & 15.3 & 13.8 & 20.2 & 12.3 & 17.0 & .12 \\
\hline
\end{tabular}

Values are expressed as \% or mean (SD). Missing $<10 \%$ of sample except prenatal diagnosis $(n=1541)$ and preoperative mechanical ventilation $(n=1305)$. $P$ values were determined by $\chi^{2}$ tests for categorical variables and Kruskal-Wallis tests for continuous variables except the BSID measures, for which analysis of variance was used. Class I, 2 ventricles with no aortic arch obstruction; Class II, 2 ventricles with aortic arch obstruction; Class III, single ventricle with no arch obstruction; and Class IV, single ventricle with arch obstruction. AVC, atrioventricular canal; IAA, interrupted aortic arch; TAPVC, total anomalous pulmonary venous connection.

(foundation models; see Table 2) were performed to determine additional independent predictors of neurodevelopmental outcome, as well as to examine temporal trends when considering all measured potential risk factors. Later year of birth was not significantly associated with better PDI or MDI when adjusting for center and cardiac class.

Independent predictors of lower PDI included lower birth weight, white race, and presence of a definite or suspected genetic or extracardiac anomaly (full model in Table 2). The final model for PDI included 1675 subjects from 22 centers with an adjusted $R^{2}$ of $24.3 \%$ and root mean square error of 16.2. A statistically significant annual improvement in PDI (0.39 points/year, $95 \%$ confidence interval [CI] 0.01 to 0.78 ; $P=.045$ ) was observed in the fully adjusted model.
Independent predictors of lower MDI included lower birth weight, male gender, less maternal education, and presence of a definite or suspected genetic or extracardiac anomaly (full model in Table 2). The final model for MDI included 1717 subjects from 22 centers with an adjusted $R^{2}$ of $27.7 \%$ and root mean square error of 14.2. A statistically significant annual improvement in MDI (0.38 points/year, $95 \%$ confidence 


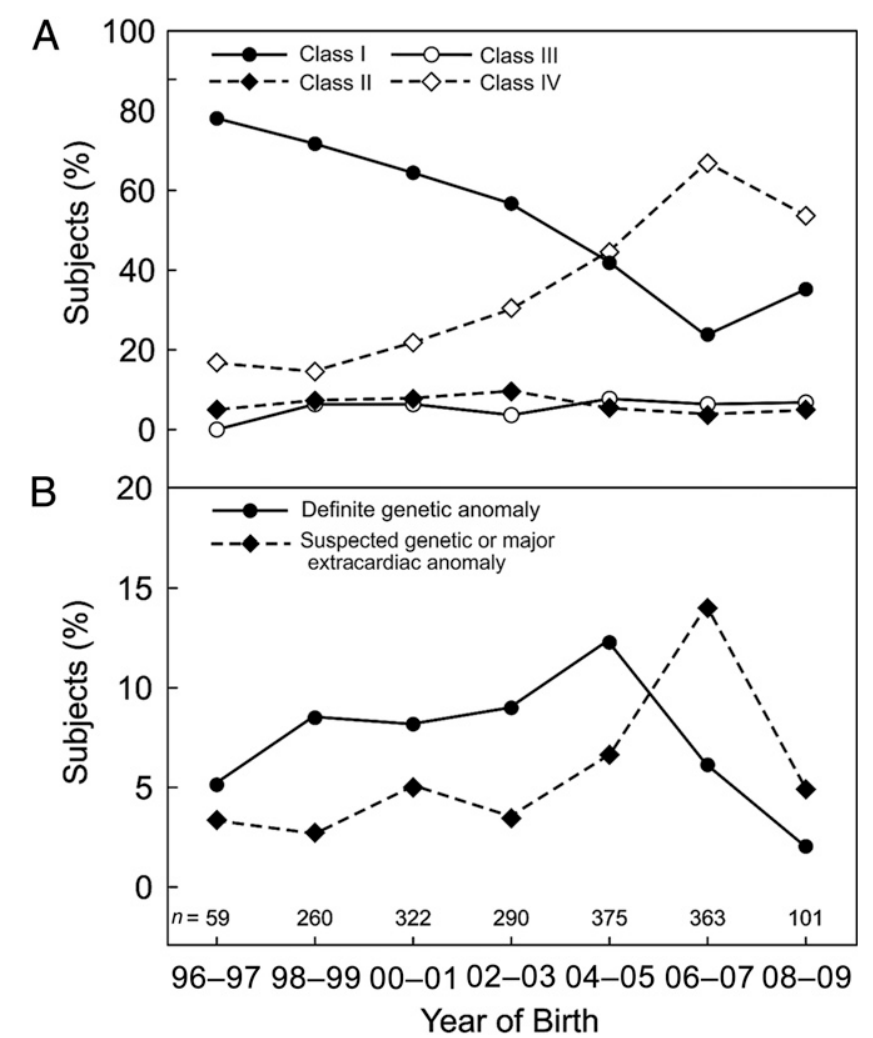

FIGURE 1

A, Distribution of cardiac class in study cohort by year of birth. Class I, 2 ventricles with no aortic arch obstruction; Class II, 2 ventricles with aortic arch obstruction; Class III, single ventricle with no arch obstruction; and Class IV, single ventricle with arch obstruction. B, Distribution of definite or suspected genetic or major extracardiac anomalies by year of birth.

interval 0.05 to $0.71 ; P=.02$ ) was observed in the fully adjusted model. Interestingly, gestational age, prenatal diagnosis, and neonatal status were not significantly associated with PDI or MDI after adjustment for the other variables in the full models.

A graphical presentation of the standardized mean PDIs and MDIs based on a model using year of birth categories and continuous year of birth with the corresponding final set of independent predictors is provided in Fig 2. In addition, relationships of PDIs and MDIs with the corresponding final set of independent predictors were examined for the homogeneous diagnostic subgroups (Table 3), including adjustment for VSD in TGA patients and adjustment for PA in TOF patients. After adjustment for patient factors, an annual improvement in scores was identified only in the TOF group.

\section{DISCUSSION}

The past 2 decades have seen dramatic improvements in survival of infants with complex CHD due to advances in surgical and perioperative care and management. ${ }^{26}$ Concomitant with diminishing early mortality rates, neurodevelopmental disabilities have been increasingly recognized in a substantial proportion of survivors. In this project, we aggregated individual participant patient factors and neurodevelopmental outcome data, measured with the same instrument, from existing studies to create the largest cohort $(>1700$ subjects) reported to date. The use of individual participant data provides the opportunity for extensive data review, allows the inclusion of unpublished data to reduce publication bias, and enables further subgroup analyses. ${ }^{12}$ We sought to use this unique dataset to determine whether improvements in neurodevelopmental performance mirrored those of survival.

Mean PDIs and MDIs were lower than expected compared with the general population. In unadjusted analyses, improvements over time were not evident in either motor function (PDI) or cognitive function (MDI). The composition of the cohort changed over the study, with an increasing number of patients with more complex CHD in the later years, likely affecting temporal trends.

Nonetheless, we could not identify significant improvements in outcomes over time, even when restricting unadjusted analyses to homogeneous diagnostic subgroups of TGA, TOF, and HLHS. Similarly, in analyses adjusting for center and complexity of CHD (ie, foundation models), we did not find improvement in either PDI or MDI over the study period. In contrast, in multivariable analyses for the whole cohort, incorporating patient and preoperative medical risk factors, performance for both PDI and MDI showed statistically significant improvements, albeit of modest magnitude. Interestingly, in multivariable analyses for the diagnostic subgroups, performance improved only for the TOF patients, but not for the TGA or HLHS groups. The absence of improved scores over time in unadjusted analyses or foundation models, but increasing scores in multivariable analyses, suggests that more patients at greater risk for adverse neurodevelopmental outcomes are undergoing congenital heart surgery and/or that high-risk patients are more often surviving.

There are several potential explanations for this finding. Patient and environmental factors, such as prematurity, genetic syndromes, and socioeconomic status, may be more important determinants of neurodevelopmental outcomes than are operative management strategies.7,9,24 Brain development is 
TABLE 2 Multivariable Linear Regression of Psychomotor and Mental Development Index With Patient Risk Factors

\begin{tabular}{|c|c|c|c|c|}
\hline \multirow[t]{2}{*}{ Variable } & \multicolumn{2}{|c|}{ PDI } & \multicolumn{2}{|c|}{ MDI } \\
\hline & Foundation Model & Full Model & Foundation Model & Full Model \\
\hline Patients (centers), $n$ & 1725 (23) & $1675(22)$ & $1768(23)$ & $1717(22)$ \\
\hline Adjusted $R^{2}, \%$ & 13.3 & 24.3 & 10.0 & 27.7 \\
\hline Root MSE & 17.5 & 16.2 & 15.8 & 14.2 \\
\hline \multicolumn{5}{|l|}{ Year of birth } \\
\hline$\beta$-estimate $(P)$ & $0.31(.14)$ & $0.39(.045)$ & $0.27(.15)$ & $0.38(.02)$ \\
\hline $95 \% \mathrm{Cl}$ & -0.10 to 0.72 & 0.01 to 0.78 & -0.10 to 0.63 & 0.05 to 0.71 \\
\hline Center, $P$ & $<.001$ & $<.001$ & $<.001$ & $<.001$ \\
\hline Cardiac class, $P$ & $<.001$ & $<.001$ & .002 & $<.001$ \\
\hline I & Reference & Reference & Reference & Reference \\
\hline \multicolumn{5}{|l|}{$\|$} \\
\hline$\beta$-estimate $(P)$ & $-0.6(.77)$ & $1.5(.39)$ & $-0.9(.58)$ & $1.3(.39)$ \\
\hline $95 \% \mathrm{Cl}$ & -4.2 to 3.1 & -1.9 to 5.0 & -4.1 to 2.3 & -1.6 to 4.2 \\
\hline \multicolumn{5}{|l|}{ III } \\
\hline$\beta$-estimate $(P)$ & $-5.3(.006)$ & $-6.1(.001)$ & $-0.2(.90)$ & $0.03(.99)$ \\
\hline $95 \% \mathrm{Cl}$ & -9.1 to -1.5 & -9.7 to -2.4 & -3.6 to 3.2 & -3.1 to 3.2 \\
\hline \multicolumn{5}{|l|}{ IV } \\
\hline$\beta$-estimate $(P)$ & $-10.7(<.001)$ & $-11.4(<.001)$ & $-4.1(<.001)$ & $-4.9(<.001)$ \\
\hline $95 \% \mathrm{Cl}$ & -13.1 to -8.3 & -13.6 to -9.1 & -6.3 to -1.9 & -6.8 to -2.9 \\
\hline \multicolumn{5}{|l|}{ Birth weight (per kg) } \\
\hline$\beta$-estimate $(P)$ & - & $3.21(<.001)$ & - & $4.38(<.001)$ \\
\hline $95 \% \mathrm{Cl}$ & - & 1.86 to 4.55 & - & 3.22 to 5.54 \\
\hline Race, $P$ & & $(.01)$ & & \\
\hline White & - & Reference & - & - \\
\hline \multicolumn{5}{|l|}{ Black } \\
\hline$\beta$-estimate $(P)$ & - & $4.6(.003)$ & - & - \\
\hline $95 \% \mathrm{Cl}$ & - & 1.5 to 7.7 & - & - \\
\hline \multicolumn{5}{|l|}{ Other } \\
\hline$\beta$-estimate $(P)$ & - & $1.4(.36)$ & - & - \\
\hline $95 \% \mathrm{Cl}$ & - & -1.6 to 4.4 & - & - \\
\hline \multicolumn{5}{|l|}{ Female gender } \\
\hline$\beta$-estimate $(P)$ & - & - & - & $2.4(<.001)$ \\
\hline $95 \% \mathrm{Cl}$ & - & - & - & 1.0 to 3.8 \\
\hline Maternal education, $P$ & & & & $<.001$ \\
\hline Graduate school & - & - & - & Reference \\
\hline \multicolumn{5}{|l|}{ Completed college } \\
\hline$\beta$-estimate $(P)$ & - & - & - & $-1.4(.26)$ \\
\hline $95 \% \mathrm{Cl}$ & - & - & - & -3.8 to 1.0 \\
\hline \multicolumn{5}{|c|}{ High school and/or some college } \\
\hline$\beta$-estimate $(P)$ & - & - & - & $-4.7(<.001)$ \\
\hline $95 \% \mathrm{Cl}$ & - & - & - & -7.0 to -2.4 \\
\hline \multicolumn{5}{|l|}{ Less than high school } \\
\hline$\beta$-estimate $(P)$ & - & - & - & $-6.8(<.001)$ \\
\hline $95 \% \mathrm{Cl}$ & - & - & - & -9.9 to -3.6 \\
\hline \multicolumn{5}{|l|}{ Missing or not specified } \\
\hline$\beta$-estimate $(P)$ & - & - & - & $-4.8(.003)$ \\
\hline $95 \% \mathrm{Cl}$ & - & - & - & -7.9 to -1.6 \\
\hline Genetic anomaly, $P$ & - & $<.001$ & - & $<.001$ \\
\hline Normal or not specified & - & Reference & - & Reference \\
\hline \multicolumn{5}{|c|}{ Suspected genetic or major extracardiac } \\
\hline$\beta$-estimate $(P)$ & - & $-8.3(<.001)$ & - & $-8.3(<.001)$ \\
\hline $95 \% \mathrm{Cl}$ & - & -11.5 to -5.1 & - & -11.1 to -5.4 \\
\hline \multicolumn{5}{|l|}{ Definite genetic } \\
\hline$\beta$-estimate $(P)$ & - & $-19.9(<.001)$ & - & $-20.8(<.001)$ \\
\hline $95 \% \mathrm{Cl}$ & - & -22.9 to -16.9 & - & -23.4 to -18.2 \\
\hline
\end{tabular}

All characteristics from Table 1 except preoperative mechanical ventilation were considered for inclusion in the models. Coefficients for intercepts and center indicator variables are not reported. MSE, mean square error, with root MSE representing the sample SD of the differences between observed and predicted values. Cl, confidence interval. —, variable not included in the corresponding model.

abnormal in children with CHD. Magnetic resonance imaging (MRI) studies in CHD fetuses show smaller total brain volumes (adjusted for gestational age and weight) and abnormal brain metabolism, as well as delayed cortical development and folding. ${ }^{27-31}$ At birth, brain maturation in neonates with HLHS or TGA is delayed by $\sim 1$ month compared with a normative sample. ${ }^{29}$ Postnatal MRI studies have shown 


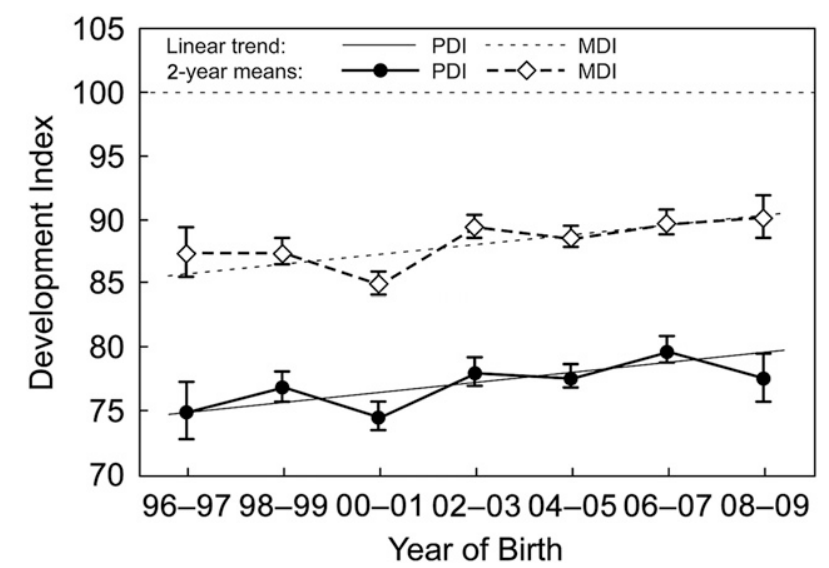

FIGURE 2

Standardized PDI and MDI means by year of birth. The standardized means plot the predicted PDIs and MDIs and SE bars based on a model with year of birth category adjusting for center, cardiac class, and other statistically significant predictors at the mean value of the covariates. Overlaid are standardized means plots based on continuous year of birth. The horizontal dotted line represents the normative mean of 100 for both PDI and MDI

that white matter injury is evident in 1 of 5 infants before cardiac surgery. ${ }^{32-34}$ Andropoulos et al showed that a lower brain maturity score at birth by MRI is associated with greater brain injury in both the preoperative and postoperative periods. ${ }^{33}$ Beca et al recently reported that severity of brain immaturity at birth predicts the severity of neurodevelopmental impairment at 2 years of age after cardiac surgery in infancy. ${ }^{34}$ In addition, von Rhein et al showed that brain volumes remain smaller into adolescence and that the magnitude of reduction correlates with neurodevelopmental outcomes. ${ }^{35}$ Thus, altered brain development due to CHD may increase vulnerability to perioperative hemodynamic instability and intraoperative brain injury due to hypoxia and ischemia. The lack of greater improvement in early neurodevelopmental outcomes over the study period, despite contemporaneous improvements in survival, surgical strategies, and perioperative care, thus may be due to the greater effects of innate patient factors and abnormal brain maturation, which outweigh the impact of modifiable management factors in determining neurodevelopmental outcomes of children with CHD.
In the latter years of the study period, a greater percentage of subjects had definite genetic anomalies. Several factors may explain this finding. Many of the early developmental studies in cardiac patients specifically excluded those with identified genetic syndromes. Additionally, genetic testing has become more prevalent in recent years and is a routine component of clinical care of complex CHD in many clinical centers. Finally, methods of discerning genetic anomalies have become increasingly sensitive, improving the yield of testing and potentially exposing abnormal genetic underpinnings to CHD that escape recognition on physical examination by subspecialists in genetics. For example, a recent study showed pathogenic copy number variants in $\geq 10 \%$ of children with single ventricle lesions, only a minority of whom were noted to be dysmorphic on examination by a clinical geneticist. ${ }^{36}$ If genetic anomalies were ascertained more frequently over time in our dataset, adjustment for genetic anomalies may have caused us to overestimate the improvement in outcomes over time.

There are limitations to this analysis. This study is not a formal metaanalysis. To develop as large a dataset as possible, investigators were asked to submit both published and unpublished data from their institutions. We did not formally assess the quality of study design and execution for each study. The trends in scores were examined over a relatively brief time interval of 14 years, during which the BSID-II was the standardized neurodevelopment test of choice at many centers. The earliest enrolled patients in our study postdated some important changes in the management of cardiopulmonary bypass for infants. Our analyses did not consider subsequent changes in intraoperative management strategies. We cannot exclude the possibility that improvement in MDI in the multivariable analyses may be the result of the Flynn effect, ie, the finding that, in the general population, cognitive function assessed by neurodevelopmental test scores improves over time by 0.3 to 0.5 points per year or $\sim 5$ points per decade. $^{37}$ In addition, early neurodevelopmental testing has limited predictive value for later neurodevelopmental outcomes. ${ }^{38,39}$ Finally, the data are assembled from existing data sets of multiple studies. Some studies were clinical trials and others were observational studies. The study designs and goals, inclusion and exclusion criteria, and data collected varied considerably. Furthermore, characteristics of the subjects in the combined dataset, such as diagnosis and surgical class, changed over the study period. Subjects in later years had greater disease severity and were more likely to have an identified genetic syndrome. All of these factors may limit generalizability of the study inferences. However, the strengths of this analysis relate to the substantial sample size, and the findings represent the consolidation of nearly all published information concerning early neurodevelopmental outcomes in this population.

\section{CONCLUSIONS}

In this analysis of pooled individual participant data, early 
TABLE 3 Multivariable Linear Regression of Psychomotor and Mental Development Index With Patient Risk Factors for Select Homogeneous Diagnostic Subgroups

\begin{tabular}{|c|c|c|c|c|c|c|}
\hline \multirow[t]{2}{*}{ Variable } & \multicolumn{2}{|c|}{ TGA } & \multicolumn{2}{|c|}{ TOF } & \multicolumn{2}{|c|}{ HLHS } \\
\hline & PDI & MDI & PDI & MDI & PDI & MDI \\
\hline Patients (centers), $n$ & 324 (9) & $334(9)$ & $174(8)$ & $179(8)$ & $541(20)$ & $549(20)$ \\
\hline Adjusted $R^{2}, \%$ & 13.6 & 22.9 & 33.6 & 37.4 & 11.5 & 20.3 \\
\hline Root MSE & 14.6 & 12.2 & 15.1 & 12.5 & 17.5 & 15.6 \\
\hline \multicolumn{7}{|l|}{ Year of birth } \\
\hline$\beta$-estimate $(P)$ & $0.07(.87)$ & $0.33(.35)$ & $1.43(.04)$ & $1.12(.0497)$ & $0.48(.19)$ & $-0.11(.73)$ \\
\hline $95 \% \mathrm{Cl}$ & -0.76 to 0.90 & -0.36 to 1.03 & 0.07 to 2.79 & 0.002 to 2.25 & -0.23 to 1.20 & -0.74 to 0.51 \\
\hline Center, $P$ & $<.001$ & $<.001$ & .01 & $<.001$ & $<.001$ & $<.001$ \\
\hline \multicolumn{7}{|l|}{ Cardiac subclass } \\
\hline \multicolumn{7}{|l|}{ Intact ventricular septum ${ }^{a}$} \\
\hline$\beta$-estimate $(P)$ & $3.6(.04)$ & $-0.8(.59)$ & - & - & - & - \\
\hline $95 \% \mathrm{Cl}$ & 0.1 to 7.1 & -3.7 to 2.1 & - & - & - & - \\
\hline \multicolumn{7}{|l|}{ No pulmonary atresia ${ }^{\mathrm{b}}$} \\
\hline$\beta$-estimate $(P)$ & - & - & $9.2(.01)$ & $3.5(.24)$ & - & - \\
\hline $95 \% \mathrm{Cl}$ & - & - & 2.1 to 16.4 & -2.4 to 9.4 & - & - \\
\hline \multicolumn{7}{|l|}{ Birth weight (per kg) } \\
\hline$\beta$-estimate $(P)$ & $2.73(.07)$ & $3.30(.007)$ & $2.77(.13)$ & $4.24(.006)$ & $2.51(.09)$ & $4.64(<.001)$ \\
\hline $95 \% \mathrm{Cl}$ & -0.17 to 5.63 & 0.89 to 5.70 & -0.84 to 6.38 & 1.26 to 7.22 & -0.40 to 5.42 & 2.05 to 7.24 \\
\hline Race, $P$ & .37 & - & .35 & - & .03 & - \\
\hline White & Reference & & Reference & & Reference & \\
\hline \multicolumn{7}{|l|}{ Black } \\
\hline$\beta$-estimate $(P)$ & $-5.0(.32)$ & - & $2.1(.72)$ & - & $4.8(.10)$ & - \\
\hline $95 \% \mathrm{Cl}$ & -14.8 to 4.9 & - & -9.6 to 13.7 & - & -0.9 to 10.5 & - \\
\hline \multicolumn{7}{|l|}{ Other } \\
\hline$\beta$-estimate $(P)$ & $2.6(.34)$ & - & $5.9(.15)$ & - & $-7.3(.05)$ & - \\
\hline $95 \% \mathrm{Cl}$ & -2.8 to 8.0 & - & -2.2 to 14.1 & - & -14.7 to 0.1 & - \\
\hline \multicolumn{7}{|l|}{ Female gender } \\
\hline$\beta$-estimate $(P)$ & - & $6.4(<.001)$ & - & $1.1(.58)$ & - & $2.6(.07)$ \\
\hline $95 \% \mathrm{Cl}$ & - & 3.5 to 9.3 & - & -2.9 to 5.1 & - & -5.5 to 0.2 \\
\hline Maternal education, $P$ & - & $<.001$ & - & .049 & - & .006 \\
\hline Graduate school & - & Reference & - & Reference & - & Reference \\
\hline \multicolumn{7}{|l|}{ Completed college } \\
\hline$\beta$-estimate $(P)$ & - & $-3.4(.19)$ & - & $6.0(.03)$ & - & $-1.7(.48)$ \\
\hline $95 \% \mathrm{Cl}$ & - & -8.6 to 1.7 & - & 0.5 to 11.5 & - & -6.6 to 3.1 \\
\hline \multicolumn{7}{|c|}{ High school and/or some college } \\
\hline$\beta$-estimate $(P)$ & - & $-9.4(<.001)$ & - & $3.0(.27)$ & - & $-6.2(.007)$ \\
\hline $95 \% \mathrm{Cl}$ & - & -14.3 to -4.4 & - & -2.3 to 8.3 & - & -10.8 to -1.7 \\
\hline \multicolumn{7}{|l|}{ Less than high school } \\
\hline$\beta$-estimate $(P)$ & - & $-13.1(<.001)$ & - & $2.3(.61)$ & - & $-7.9(.02)$ \\
\hline $95 \% \mathrm{Cl}$ & - & -19.2 to -6.9 & - & -6.6 to 11.3 & - & -14.3 to -1.5 \\
\hline \multicolumn{7}{|l|}{ Missing or not specified } \\
\hline$\beta$-estimate $(P)$ & - & $-6.8(.03)$ & - & $-13.0(.10)$ & - & $-6.8(.02)$ \\
\hline $95 \% \mathrm{Cl}$ & - & -13.0 to -0.5 & - & -28.5 to 2.5 & - & -12.5 to -1.1 \\
\hline Genetic anomaly, $P$ & .01 & $<.001$ & $<.001$ & $<.001$ & $<.001$ & $<.001$ \\
\hline Normal or not specified & Reference & Reference & Reference & Reference & Reference & Reference \\
\hline \multicolumn{7}{|c|}{ Suspected genetic or major extracardiac } \\
\hline$\beta$-estimate $(P)$ & $-16.8(.03)$ & $-13.8(.03)$ & $-18.6(.005)$ & $-22.4(<.001)$ & $-7.9(<.001)$ & $-6.8(.001)$ \\
\hline $95 \% \mathrm{Cl}$ & -31.7 to -2.0 & -26.2 to -1.4 & -31.4 to -5.8 & -33.1 to -11.6 & -12.6 to -3.3 & -10.9 to -2.7 \\
\hline \multicolumn{7}{|l|}{ Definite genetic } \\
\hline$\beta$-estimate $(P)$ & $-23.2(.03)$ & $-28.3(<.001)$ & $-22.6(<.001)$ & $-20.3(<.001)$ & $-18.5(<.001)$ & $-21.5(<.001)$ \\
\hline $95 \% \mathrm{Cl}$ & -44.2 to -2.3 & -42.6 to -14.1 & -29.8 to -15.5 & -25.9 to -14.6 & -27.4 to -9.5 & -29.2 to -13.7 \\
\hline
\end{tabular}

$\mathrm{Cl}$, confidence interval; MSE, mean square error, with root MSE representing the sample SD of the differences between observed and predicted values. - variable not included in the corresponding model.

a In comparison with ventricular septal defect.

b In comparison with pulmonary atresia.

neurodevelopmental outcomes after cardiac surgery in newborns and infants are below population means and, even after adjustment for center and class, have not significantly improved in recent years. After adjustment for patient and preoperative medical factors, however, both PDI and MDI improved significantly by a modest degree ( 5-6 points over 14 years). Multivariable regression analyses 
showed that patient factors (race, gender, birth weight, genetic anomalies, type of CHD, and maternal education) are important determinants of neurodevelopmental outcomes. To the extent that subjects in this study reflect true temporal trends, these data suggest that more high-risk CHD infants are undergoing cardiac surgery and surviving, creating a growing population that will require significant societal resources.

Mr Stopp and Dr Wypij coordinated and created the pooled data set and carried out the analyses; Drs Gaynor and Newburger drafted the initial manuscript; and all authors reviewed and revised the manuscript and approved the final manuscript as submitted.

www.pediatrics.org/cgi/doi/10.1542/peds.2014-3825

DOI: $10.1542 /$ peds.2014-3825

Accepted for publication Feb 24, 2015

Address correspondence to J. William Gaynor, MD, Division of Cardiothoracic Surgery, The Children's Hospital of Philadelphia, 34th and Civic Center Blvd, Philadelphia, PA 19104. E-mail: gaynor@email.chop.edu

PEDIATRICS (ISSN Numbers: Print, 0031-4005; Online, 1098-4275)

Copyright (C) 2015 by the American Academy of Pediatrics

FINANCIAL DISCLOSURE: The authors have indicated they have no financial relationships relevant to this article to disclose.

FUNDING: This pooled data analysis project was funded by a grant from the Mend-a-Heart Foundation. The Kostin Family Innovation Fund supplied partial support for Mr Stopp. Individual studies that contributed data were funded by grants from the American Heart Association (9950480N, 0365018Y), Auckland Medical Research Fund, Australia and New Zealand Intensive Care Society, Canadian Institutes of Health Research (M0P93780), CReFF (Clinical Research Feasibility Fund) Grant, Children's National Medical Center Board of Visitors Grant, Doris Duke Foundation, Ethel Brown Foerderer Fund for Excellence, Farb Family Fund, Food and Drug Administration's Office of Orphan Products Development, Green Lane Research and Education Fund, Heart Foundation of New Zealand, Internal Children's National Medical Center Grants, Larry L. Hillblom Foundation (2002/3E), March of Dimes Foundation (5-FY2005-1231, 6-FY2009-303), Mercator Foundation Switzerland, Murdoch Children's Research Institute, National Center for Research Resources (RR01271, RR02172), National Heart Foundation of Australia, National Heart, Lung, and Blood Institute (HL41786, HL063411, HL068269, HL068270, HL068279, HL068281, HL068285, HL068288, HL068290, HL068292, HL085057), National Institute of Child Health and Development (HD18655, HD055501), National Institute of Neurologic Disorders and Stroke (NS35902, NS40117, NS063876), and Prince Charles Hospital Foundation.

POTENTIAL CONFLICT OF INTEREST: The authors have indicated they have no potential conflicts of interest to disclose.

COMPANION PAPER: A companion to this article can be found on page 926, and online at www.pediatrics.org/cgi/doi/10.1542/peds.2015-0719.

\section{REFERENCES}

1. Bhutta AT, Cleves MA, Casey PH, Cradock MM, Anand KJ. Cognitive and behavioral outcomes of school-aged children who were born preterm: a meta-analysis. JAMA. 2002;288(6):728-737

2. Bellinger DC, Wypij D, Rivkin MJ, et al. Adolescents with d-transposition of the great arteries corrected with the arterial switch procedure: neuropsychological assessment and structural brain imaging. Circulation. 2011;124(12):1361-1369

3. Gaynor JW, Nord AS, Wernovsky G, et al. Apolipoprotein $\mathrm{E}$ genotype modifies the risk of behavior problems after infant cardiac surgery. Pediatrics. 2009;124(1). Available at: www.pediatrics.org/cgi/ content/full/124/1/e241

4. Creighton DE, Robertson CMT, Sauve RS, et al; Western Canadian Complex Pediatric Therapies Follow-up Group. Neurocognitive, functional, and health outcomes at 5 years of age for children after complex cardiac surgery at 6 weeks of age or younger. Pediatrics. 2007;120(3). Available at: www.pediatrics. org/cgi/content/full/120/3/e478

5. Neufeld RE, Clark BG, Robertson CM, et al. Five-year neurocognitive and health outcomes after the neonatal arterial switch operation. J Thorac Cardiovasc Surg. 2008;136(6):1413-1421

6. Bellinger DC, Newburger JW, Wypij D, Kuban KC, duPlesssis AJ, Rappaport LA. Behaviour at eight years in children with surgically corrected transposition: the Boston Circulatory Arrest Trial. Cardiol Young. 2009;19(1):86-97

7. Gaynor JW, Wernovsky G, Jarvik GP, et al Patient characteristics are important determinants of neurodevelopmental outcome at one year of age after neonatal and infant cardiac surgery. J Thorac Cardiovasc Surg. 2007;133(5): 1344-1353, e1-e3

8. Gaynor JW, Gerdes M, Zackai EH, et al. Apolipoprotein E genotype and neurodevelopmental sequelae of infant cardiac surgery. J Thorac Cardiovasc Surg. 2003;126(6):1736-1745

9. Atallah J, Dinu IA, Joffe AR, et al; Western Canadian Complex Pediatric Therapies Follow-Up Group. Two-year survival and mental and psychomotor outcomes after the Norwood procedure: an analysis of the modified Blalock-Taussig shunt and right ventricle-to-pulmonary artery shunt surgical eras. Circulation. 2008; 118(14):1410-1418

10. Debray TP, Moons KG, Ahmed I, Koffijberg $H$, Riley RD. A framework for developing, implementing, and evaluating clinical prediction models in an individual participant data meta-analysis. Stat Med. 2013;32(18):3158-3180

11. Abo-Zaid G, Sauerbrei W, Riley RD Individual participant data meta-analysis of prognostic factor studies: state of the art? BMC Med Res Methodol. 2012; 12(1):56 
12. Stewart LA, Tierney JF. To IPD or not to IPD? Advantages and disadvantages of systematic reviews using individual patient data. Eval Health Prof. 2002;25(1): 76-97

13. Bayley N. Manual for the Bayley Scales of Infant Development, 2nd ed. San Antonio, TX: Pyschological Corporation; 1969

14. Bayley N. Bayley Scales of Infant and Toddler Development. San Antonio, TX: Pearson Education, Inc; 2006

15. Fuller S, Nord AS, Gerdes M, et al. Predictors of impaired neurodevelopmental outcomes at one year of age after infant cardiac surgery. Eur J Cardiothorac Surg. 2009;36(1):40-47

16. Bellinger DC, Wypij D, du Plessis AJ, et al. Developmental and neurologic effects of alpha-stat versus pH-stat strategies for deep hypothermic cardiopulmonary bypass in infants. J Thorac Cardiovasc Surg. 2001;121(2):374-383

17. Newburger JW, Jonas RA, Soul J, et al. Randomized trial of hematocrit $25 \%$ versus 35\% during hypothermic cardiopulmonary bypass in infant heart surgery. J Thorac Cardiovasc Surg. 2008; 135(2):347-354

18. Wypij D, Jonas RA, Bellinger DC, et al. The effect of hematocrit during hypothermic cardiopulmonary bypass in infant heart surgery: results from the combined Boston hematocrit trials. J Thorac Cardiovasc Surg. 2008;135(2):355-360

19. Bellinger DC, Jonas RA, Rappaport LA, et al. Developmental and neurologic status of children after heart surgery with hypothermic circulatory arrest or low-flow cardiopulmonary bypass. $N$ Engl J Med. 1995;332(9):549-555

20. Goldberg CS, Bove EL, Devaney EJ, et al. A randomized clinical trial of regional cerebral perfusion versus deep hypothermic circulatory arrest: outcomes for infants with functional single ventricle. J Thorac Cardiovasc Surg. 2007;133(4):880-887

21. Newburger JW, Sleeper LA, Bellinger DC, et al; Pediatric Heart Network Investigators. Early developmental outcome in children with hypoplastic left heart syndrome and related anomalies: the single ventricle reconstruction trial. Circulation. 2012;125(17):2081-2091
22. Ravishankar C, Zak V, Williams IA, et al; Pediatric Heart Network Investigators. Association of impaired linear growth and worse neurodevelopmental outcome in infants with single ventricle physiology: A report from the Pediatric Heart Network infant single ventricle trial. J Pediatr. 2013;162(2):250-256, e2

23. Robertson DR, Justo RN, Burke CJ, Pohlner PG, Graham PL, Colditz PB. Perioperative predictors of developmental outcome following cardiac surgery in infancy. Cardiol Young. 2004;14(4):389-395

24. Atallah J, Joffe AR, Robertson CMT, et al; Western Canadian Complex Pediatric Therapies Project Follow-up Group. Twoyear general and neurodevelopmental outcome after neonatal complex cardiac surgery in patients with deletion 22q11.2: a comparative study. J Thorac Cardiovasc Surg. 2007;134(3):772-779

25. Clancy RR, McGaurn SA, Wernovsky G, et al. Preoperative risk-of-death prediction model in heart surgery with deep hypothermic circulatory arrest in the neonate. J Thorac Cardiovasc Surg. 2000;119(2):347-357

26. Oster ME, Lee KA, Honien MA, RiehleColarusso T, Shin M, Correa A. Temporal trends in survival among infants with critical congenital heart defects. Pediatrics. 2013;131(5). Available at: www.pediatrics.org/cgi/content/full/131/ 5/e1502

27. Miller SP, McQuillen PS, Hamrick S, et al Abnormal brain development in newborns with congenital heart disease [see comment]. N Engl J Med. 2007; 357(19):1928-1938

28. Limperopoulos C, Tworetzky W, McElhinney DB, et al. Brain volume and metabolism in fetuses with congenital heart disease: evaluation with quantitative magnetic resonance imaging and spectroscopy. Circulation. 2010;121(1):26-33

29. Licht DJ, Shera DM, Clancy RR, et al. Brain maturation is delayed in infants with complex congenital heart defects. J Thorac Cardiovasc Surg. 2009;137(3): 529-536, discussion 536-537

30. Clouchoux C, Kudelski D, Gholipour A, et al. Quantitative in vivo MRI measurement of cortical development in the fetus. Brain Struct Funct. 2012; 217(1):127-139

31. Ortinau C, Beca J, Lambeth J, et al. Regional alterations in cerebral growth exist preoperatively in infants with congenital heart disease. J Thorac Cardiovasc Surg. 2012;143(6):1264-1270

32. Licht DJ, Wang J, Silvestre DW, et al. Preoperative cerebral blood flow is diminished in neonates with severe congenital heart defects. J Thorac Cardiovasc Surg. 2004;128(6):841-849

33. Andropoulos DB, Hunter JV, Nelson DP, et al. Brain immaturity is associated with brain injury before and after neonatal cardiac surgery with high-flow bypass and cerebral oxygenation monitoring. $J$ Thorac Cardiovasc Surg. 2010;139(3): 543-556

34. Beca J, Gunn JK, Coleman L, et al. New white matter brain injury after infant heart surgery is associated with diagnostic group and the use of circulatory arrest. Circulation. 2013; 127(9):971-979

35. von Rhein M, Buchmann A, Hagmann C, et al. Brain volumes predict neurodevelopment in adolescents after surgery for congenital heart disease. Brain. 2014;137 (Pt 1):268-276

36. Carey AS, Liang L, Edwards J, et al. Effect of copy number variants on outcomes for infants with single ventricle heart defects. Circ Cardiovasc Genet. 2013;6(5): 444-451

37. Flynn JR. The mean IQ of Americans: Massive gains 1932-1978. Psychol Bull. 1984;95:29-51

38. McGrath E, Wypij D, Rappaport LA, Newburger JW, Bellinger DC. Prediction of IQ and achievement at age 8 years from neurodevelopmental status at age 1 year in children with D-transposition of the great arteries. Pediatrics. 2004; 114(5). Available at: www.pediatrics.org/ cgi/content/full/114/5/e572

39. Goldberg CS, Lu M, Sleeper LA, et al; Pediatric Heart Network Investigators Factors associated with neurodevelopment for children with single ventricle lesions. J Pediatr. 2014; 165(3):490-496, e8 